\title{
Phenolic Compounds in Acerola Fruit (Malpighia punicifolia, L.)
}

\author{
Ana Lúcia A. Vendramini* and Luiz C. Trugo* \\ Instituto de Química, Universidade Federal do Rio de Janeiro, Ilha do Fundão, CT bloco A, sala 528, \\ 21949-900 Rio de Janeiro - RJ, Brazil
}

\begin{abstract}
Agliconas de antocianinas e outros compostos fenólicos foram identificados na fruta acerola (Malpighia punicifolia, L). As antocianinas, os flavonóides e os ácidos fenólicos foram fracionados e caracterizados através de dados cromatográficos e espectrais. O teor de antocianinas na casca da acerola madura foi $37,5 \mathrm{mg} 100 \mathrm{~g}^{-1}$. Os pigmentos fenólicos identificados foram a pelargonidina, a malvidina 3,5-diglicosilada e a cianidina 3-glicosilada. Foram também identificados a quercetina, o kaempferol, e os ácidos p-cumárico, ferúlico, cafeico e clorogênico.
\end{abstract}

Anthocyanin aglycons and other phenolic compounds were identified in acerola (Malpighia punicifolia, $L$.). Anthocyanins, flavonoids and phenolic acids were fractionated and characterized by means of chromatographic and spectral data. The total content of anthocyanin pigments was $37.5 \mathrm{mg}$ per $100 \mathrm{~g}$ of ripe acerola skin. The phenolic pigments identified were pelargonidin, malvidin 3,5diglycoside and cyanidin 3-glycoside. Quercetin, kaempferol and the phenolic acids p-coumaric acid, ferulic, caffeic and chlorogenic were also identified.

Keywords: flavonoids, anthocyanins, phenolic acids, acerola, Malpighia punicifolia L.

\section{Introduction}

Phenolic compounds are important for plant metabolism and have also becoming important for humans due to their health characteristics, particularly related to their antioxidant properties. ${ }^{1}$

Anthocyanins are one of the most attractive plant phenolic pigments of the group of flavonoids. Their visual impact allied to their health properties make them potentially useful as natural food colorants.

One possible source of anthocyanin pigments is the fruit of acerola (Malpighia punicifolia, L.), a highly productive plant, which provides fruits during long periods of the year and is extensively cultivated in Brazil. The attractive red colour in acerola skin is mainly due to anthocyanins and the abundance of this fruit in Brazil represents a potential source of anthocyanin pigments.

Flavonoids are polyphenolic compounds that occur ubiquitously in food of plant origin and more than 2000 chemically distinct flavonoids have been already reported. ${ }^{2}$

Phenolic compounds are also important because of their contribution to the sensory quality of fruits (colour and flavour, including astringency and bitterness) which may

*e-mail: lctrugo@iq.ufrj.br; alvendra@ms.microlink.com.br be affected during the technological processes used for production of juice and other derived products. ${ }^{3}$ In addition, anthocyanins and other phenolic compounds have been used successfully in the characterization of fruits and juices. ${ }^{4}$

Due to the importance of flavonoids, many techniques have been used to identify and quantify these compounds. In the early 1990s, high-performance liquid chromatography (HPLC), with photodiode array detection was used to isolation and quantification. ${ }^{1} \mathrm{H}$ and ${ }^{13} \mathrm{C} \mathrm{NMR}$ spectroscopy are the most powerful techniques for determination of molecular structure. The coupling of HPLC and mass spectrometry methods, such as electrospray, thermospray, or fast-atom bombardment, have been widely used to provide molecular weight and characteristic fragment ions for structural elucidation ${ }^{2}$, but these are very expensive techniques which are not readily available. ${ }^{5}$ Due to simplicity of methodology and low cost, techniques like paper chromatography and thin-layer chormatography have been applied routinely in many laboratories. ${ }^{2,6-8}$

Acerola skin is a byproduct of acerola processing usually discarded in juice and pulp industries and due to its relatively high levels of anthocyanins it could be exploited as a potential source of these pigments. The interest in identifying sources of anthocyanin pigments to 
be used in food, pharmaceutical and cosmetic industries is based on consumer demand for natural colorants, and on the nutraceutical properties frequently reported for flavonoids. ${ }^{9}$ However, as far as we know, no studies on characterization of acerola phenolics have been published. Thus, the objective of the present work was to isolate and characterize the phenolic compounds present in acerola and to estimate the amount of anthocyanin pigments found in the acerola skin which is usually a by product from the production of acerola pulp.

\section{Material and Methods}

\section{Fruit}

Acerola fruits (M. punicifolia, L.) were chosen by intensive red colour, firmness and a pleasant acid flavour, which are indicative of an ideal stage of ripeness. The fruits were harvested during June 2000 in a commercial plantation in Rio de Janeiro city (Brazil). After harversting, the fruits were washed, packed in polyethylene bags and stored in the dark at $-18{ }^{\circ} \mathrm{C}$ for two days before anthocyanin extraction.

\section{Chemicals}

Caffeic, ferulic, p-coumaric and chlorogenic acids and quercetin, kaempferol, myricetin, and pelargonidin chloride, were obtained from Sigma Chemical Co (USA). The solvents used were of HPLC grade obtained from Tedia Co (USA). All other chemicals were of analytical grade.

\section{HPLC equipment}

A Pharmacia (Switzerland) liquid chromatographic system, equipped with two pumps (LKB model 2248), a controller (LKB model LCC 2252), and an injector motor valve (model PMV-7) with $20 \mu \mathrm{L}$ loop was used. The system was attached to a UV-VIS detector SPD 10 AV (Shimadzu Japan). An integrator model C-R6A (Shimadzu - Japan) was used for data processing.

\section{Characterization of anthocyanin aglycones}

Anthocyanins were analyzed in the extract from acerola skin where these pigments are concentrated. The skin of ripe acerola fruit $(500 \mathrm{~g})$ was extracted with $600 \mathrm{~mL}$ of acidified methanol $(0.1 \%$ citric acid, v/v) in the dark at about $15{ }^{\circ} \mathrm{C}$ and the extract concentrated under vacuum. Due to the non-availability of standards, anthocyanin characterization was carried out based on several physico- chemical information such as mobility in HPLC, separation by paper chromatography and spectroscopic characteristics. Paper chromatographic separation was performed in the dark using Whatman paper $3 \mathrm{MM} \mathrm{Chr}(23$ x $57 \mathrm{~cm})$ according to the method described by Francis. ${ }^{10}$ Analysis of HPLC was performed in a Lichrospher-100 RP-18 column (250 x $4.6 \mathrm{~mm}$, Merck, Germany) using methanolwater $(1: 1, \mathrm{v} / \mathrm{v})$ acidified with $2 \mathrm{~mol} \mathrm{~L}^{-1} \mathrm{HCl}$ as mobile phase until $\mathrm{pH} 2.5$ and flow rate of $1.3 \mathrm{~mL} \mathrm{~min}^{-1}$. Detection was carried out at $530 \mathrm{~nm} .{ }^{11} \mathrm{UV}-\mathrm{Vis}$ spectroscopy was carried out in the fractions separated by paper chromatography that were dissolved in methanolic $0.01 \% \mathrm{HCl}$. UVVis spectra were obtained with a Beckman DU 650 spectrophotometer (Fullerton, USA), in the range of 200 - $600 \mathrm{~nm}$, with the absorption spectra registered before and after the addition of 3 drops of a solution of the aluminum chloride salt in absolute ethanol $(5 \% \mathrm{~m} / \mathrm{v}) .^{8,12-14}$ The position of the sugar in the anthocyanin molecule was assigned based on the spectral shifts by calculation of the ratio of absorption at $440 \mathrm{~nm}$ to the specific absorption maximum for each pigment. ${ }^{8,13,14}$ The amount of total anthocyanin in the acerola skin was estimated based on the calculation described by Lees and Francis ${ }^{15}$ after measurement of the absorbance of the acidified ethanol extract at $535 \mathrm{~nm}$.

\section{Characterization of flavonols and phenolic acids}

Flavonols and phenolic acids are distributed both in the fruit skin and pulp. Consequently, in order to obtain a higher yield, the whole fruit was used for extraction. Frozen acerola fruit $(260 \mathrm{~g}$ ) was blended with $250 \mathrm{~mL}$ of cooled distilled water and centrifuged at $3000 \mathrm{x} \mathrm{g}$ for $20 \mathrm{~min}$ at $4{ }^{\circ} \mathrm{C}$. The extraction and centrifugation procedures were repeated twice. The combined supernatants were filtered through Whatman No.1 filter paper. Selective solvent extractions were then carried out to obtain one fraction containing the flavonol aglycons and other containing the phenolic acids, following the procedure described by Kader et al. ${ }^{16}$ Characterization was then carried out using HPLC for separation and identification was done by comparison and spiking with external standards. For the analysis of flavonol aglycons, the mobile phase was methanol containing $0.5 \%$ orthophosphoric acid $(1: 1 \mathrm{v} / \mathrm{v})$ with a flow rate of $1.2 \mathrm{~mL} / \mathrm{min}$., and detection at $370 \mathrm{~nm} .{ }^{17}$ For the analysis of the phenolic acids, the mobile phase consisted of a gradient elution with $0.01 \mathrm{~mol} \mathrm{~L}^{-1}$ tri-sodium citrate solution and $20 \%$ methanol adjusted to $\mathrm{pH} 2.5$ with

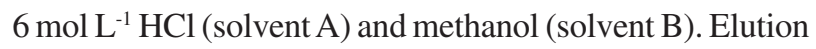
was performed at a flow rate of $1.0 \mathrm{~mL} / \mathrm{min}$ with the gradient of $5 \mathrm{~min}$ for B, increasing to $19 \%$ in $15 \mathrm{~min}, 20 \%$ in $5 \mathrm{~min}, 30 \%$ in $10 \mathrm{~min}$ and $50 \%$ in $10 \mathrm{~min}$. Detection was 
at $325 \mathrm{~nm} .{ }^{18}$ In both cases, a Lichrospher-100 RP-18 column (250 x $4.6 \mathrm{~mm}, 5 \mu \mathrm{m}$, Merck, Germany) was used.

\section{Results and Discussion}

The main objective of the present study was to characterize the phenolic compounds present in acerola, including the aglycones of phenolic glycosides. The structures of the compounds studied are shown in Figure 1. Phenolic pigments such as anthocyanins are usually found as glycosides in plants, however, when they are ingested as food the sugars are easily hydrolyzed from the<smiles>[R]c1cc(-c2[o+]c3cc(O)cc(O)c3cc2O)cc([R])c1O</smiles>

a) Acerola anthocyanins and anthocyanidin:

1 Malvidin 3,5-diglucoside $\left(\mathrm{R}^{1}=\mathrm{R}^{2}=\mathrm{OCH}_{3}, \mathrm{R}^{3}=\mathrm{R}^{4}=\right.$ glucose $)$ 2 Cyanidin 3-glucoside $\left(R^{1}=O H, R^{2}=R^{4}=H, R^{3}=\right.$ glucose) 3 Pelargonidin $\left(R^{1}=R^{2}=R^{3}=R^{4}=H\right)$

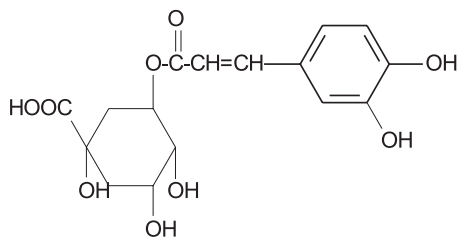

b) Acerola phenolic acids

4 clorogenic acid

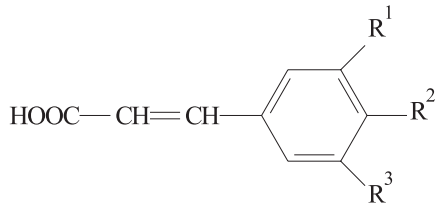

c) Acerola phenolic acids

5 caffeic acid $\left(R^{1}=H, R^{2}=R^{3}=O H\right)$

6 -coumaric acid $\left(\mathrm{R}^{1}=\mathrm{R}^{3}=\mathrm{H}, \mathrm{R}^{2}=\mathrm{OH}\right)$

7 ferulic acid $\left(\mathrm{R}^{1}=\mathrm{H}, \mathrm{R}^{2}=\mathrm{OH}, \mathrm{R}^{3}=\mathrm{OCH}_{3}\right)$<smiles>[R]c1cc(-c2oc3cc(O)cc(O)c3c(=O)c2O)cc([R])c1O</smiles>

d) Acerola flavonols:

8 Quercetin $\left(\mathrm{R}^{1}=\mathrm{OH}, \mathrm{R}^{2}=\mathrm{H}\right)$

9 Kaempferol $\left(R^{1}=R^{2}=H\right)$

Figure 1. Chemical structure of phenolic compounds identified in acerola. aglycones. HPLC analysis of the anthocyanin fraction showed three peaks with retention times of $5.7 \mathrm{~min}, 14.9$ min and $22.1 \mathrm{~min}$ (Figure 2). Similarly, paper chromatography revealed three bands with pink, magenta and orange colours, respectively. The typical order of chromatographic elution in reverse phase HPLC of different anthocyanins with similar glycosylation patterns is determined by the polarity of the aglycone. The three peaks observed in the HPLC chromatogram were correspondent to the three bands observed by descending paper chromatography. Peak 1 corresponded to the pink band $(\mathrm{Rf}=0.43)$; peak 2 corresponded to the magenta band $(\mathrm{Rf}=0.12)$ and peak 3 to the orange band $(\mathrm{Rf}=0.56)$. The different colours of anthocyanin pigments reflect the nature of their hydroxylation and methoxylation patterns. An increase in hydroxylation is accompanied by an increase in blue colour while methoxylation enhances the red colour. ${ }^{1}$ This would indicate that peak 1 may correspond to a malvidin with one methoxylation and peak 2 to a cianidin with two hydroxylations. Peak 3 indicates one hydroxylation in the molecule which confirms the assignment of pelargonidin that was determined by comparison and spiking with the external standard.

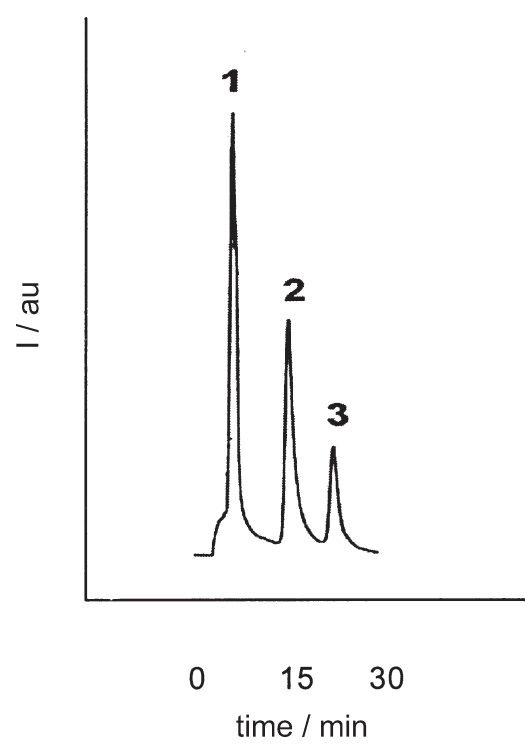

Figure 2. HPLC chromatogram of the methanolic extract of acerola. Column: Lichrospher - $100 \mathrm{RP} 18$ (250 x $4.6 \mathrm{~mm})$; eluent: methanol/water $(1: 1 \mathrm{v} / \mathrm{v}) \mathrm{pH} 2.5$; flow-rate: $1.3 \mathrm{~mL} \mathrm{~min}^{-1}$; detection: 530 nm; Peaks: 1, malvidin 3,5-diglycoside (5.7 min); 2, cyanidin 3 glycoside (14.9 $\mathrm{min})$; 3, pelargonidin (22.1 $\mathrm{min})$.

Additional qualitative information was obtained with the aid of the spectral characteristics of the chromatographic bands. The spectral data presented in Table 1 show the maximum absorptions for the chromatographic peaks as 277 and $536 \mathrm{~nm}$ for peak 1 (5.7 $\mathrm{min}) ; 281$ and $527 \mathrm{~nm}$ 
Table 1. Data of anthocyanin pigments from acerola

\begin{tabular}{ccccccc}
\hline $\begin{array}{c}\text { Rf (\%) of bands } \\
\text { from paper } \\
\text { chromatography }\end{array}$ & $\lambda_{\max }(\mathrm{nm})$ & $\mathrm{Abs}_{\lambda 440 \mathrm{~nm}} / \mathrm{Abs}_{\lambda \text { vis max }}$ & $\mathrm{AlCl}_{3}$ shift & $\begin{array}{c}\mathrm{HPLC} \mathrm{t}_{\mathrm{R}} \\
(\mathrm{min} .)\end{array}$ & $\begin{array}{c}\text { Relative amount } \\
\text { (\% of peak area) }\end{array}$ & Peak Assignment \\
\hline 43 & $277 ; 536$ & 11 & - & 5.7 & 68 & Malvidin 3,5-diglycoside \\
12 & $281 ; 527$ & 24 & + & 14.9 & 21 & $\begin{array}{c}\text { Cyanidin 3-glycoside } \\
\text { Pelargonidin }\end{array}$ \\
56 & $266 ; 523$ & 35 & - & 22.1 & 11 & \\
\hline
\end{tabular}

for peak 2 (14.9 min) and 266 and $523 \mathrm{~nm}$ for peak 3 (22.1 min). These data are correspondent to spectral data of malvidin, cyanidin and pelargonidin. ${ }^{7,10-12,19}$

No change in colour was observed after addition of aluminum chloride in the fractions corresponding to peaks 1 and 3 , but the one corresponding to peak 2 changed from red to blue as a consequence of a shift in the maximum of absorption. This is an indication that peak 2 is an orthodihydroxy anthocyanin belonging to the groups of pelargonidin, peonidin or malvidin. ${ }^{19}$ This test enables to make a broad differentiation between the derivatives of the cyanidin, delphinidin and petunidin groups, which show a positive colour change, and those of the pelargonidin, peonidin and malvidin groups, which show no colour change. ${ }^{19}$ These results further support the assignment of peak 3 as pelargonidin and indicate that peak 1 does not belong to the cianidin, delphinidin or petunidin groups.

The ratios of $\mathrm{Abs}_{440} / \mathrm{Abs}_{\lambda \max }$ calculated for peaks 1, 2 and 3 were 11, 24 and 35, respectively. The ratio of absorption at 440nm to the maximum is useful in distinguishing anthocyanins when glycosilated at the 3and 5- positions. ${ }^{11,13}$ The $\mathrm{Abs}_{440} / \mathrm{Abs}_{\lambda \max }$ ratio is usually about 11 for malvidin, corresponding to 3,5-diglycosides. The $\mathrm{Abs}_{440} / \mathrm{Abs}_{\lambda \max }$ ratio is 24 for cyanidin derivatives substituted at position 3 and is 35 for pelargonidin which is not glycosilated. ${ }^{11,13}$

The results obtained in the present work are in agreement with literature data ${ }^{7,13,19,20}$ for the assignment of a malvidin 3,5-diglycoside as peak 1 and a cyanidin 3monoglycoside as peak 2.

Absence of absorption in the 308-328 $\mathrm{nm}$ region of the spectra indicated that none of the acerola pigments were acylated with aromatic organic acid. ${ }^{20}$

The content of anthocyanins was estimated as $37.5 \mathrm{mg}$ per $100 \mathrm{~g}$ of ripe acerola skin. This anthocyanin content is higher than that found in red cabbage $(25 \mathrm{mg})$, plum (2 $25 \mathrm{mg}$ ), strawberries $(15-35 \mathrm{mg}$ ) and banana bracts (32 mg) per $100 \mathrm{~g}$ fresh weight. ${ }^{14,21}$ This indicates that acerola skin which is a by product of the acerola pulp production may be used as a commercial source of natural pigment.

Qualitative HPLC analysis and identification by means of spiking and comparison with external standards were carried out in the fraction containing phenolic acids. Two major peaks were identified as p-coumaric and ferulic acid (peaks 6 and 7). Smaller peaks corresponding to chlorogenic acid (5-caffeoylquinic acid), and caffeic acid (peaks 4 and 5, respectively) were also detected in the fraction (Figure 3).

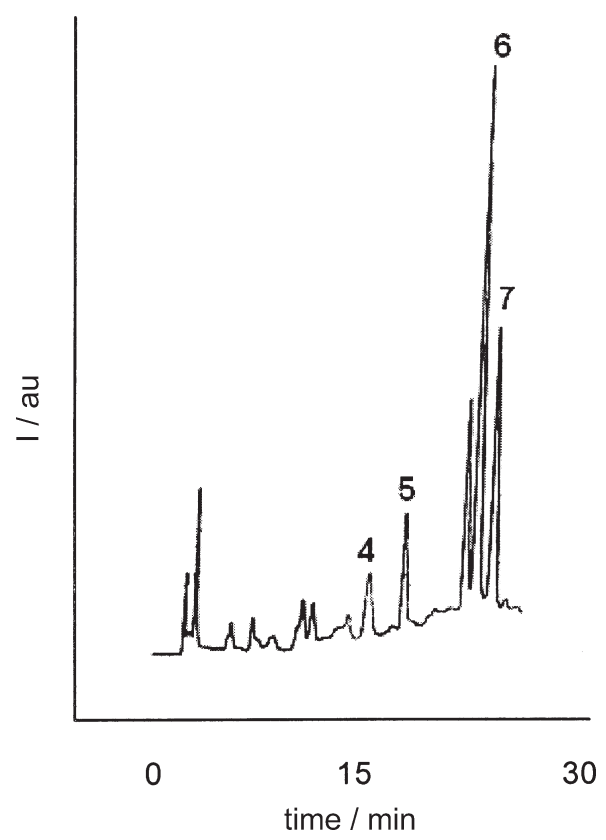

Figure 3. HPLC chromatogram of the phenolic acids extract of acerola. Column: Lichrospher - $100 \mathrm{RP} 18$ (250 x $4.6 \mathrm{~mm})$; eluent: $0.01 \mathrm{~mol} \mathrm{~L}^{-1}$ tri-sodium citrate solution and $20 \%$ methanol (solvent

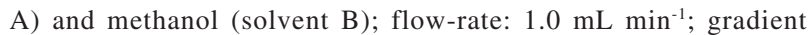
elution: $5 \mathrm{~min}$ for $\mathrm{B}$, increasing to $19 \%$ in $15 \mathrm{~min}, 20 \%$ in $5 \mathrm{~min}$, $30 \%$ in $10 \mathrm{~min}$ and $50 \%$ in $10 \mathrm{~min}$; detection: $325 \mathrm{~nm}$. Peaks: 4 , chlorogenic acid (17.5 min); 5, caffeic acid (20.2 min); 6, p-coumaric acid $(25.9 \mathrm{~min}) ; 7$, ferulic acid $(27.2 \mathrm{~min})$.

Caracterization of flavonol aglycons is also important due to their biological activities particularly in relation to their antioxidant properties. ${ }^{9,22-24}$ The fraction containing flavonol aglycons showed as expected maximum absorbance at $370 \mathrm{~nm}$. Individual peaks obtained by HPLC were assigned after comparison of retention times and coelution with flavonol standards showing the presence of quercetin (Rt $8.2 \mathrm{~min}$ ) and kaempferol (Rt $13.0 \mathrm{~min}$ ) (Figure 4). 


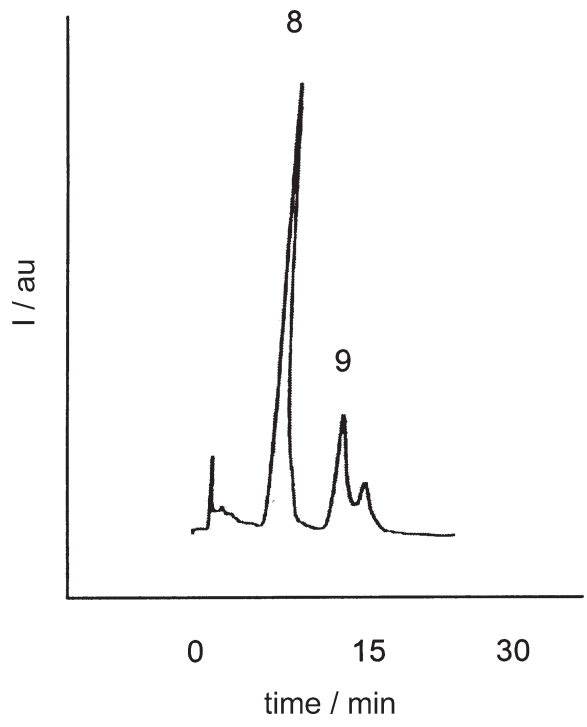

Figure 4. HPLC chromatogram of the flavonol aglycons extract of acerola. Column: Lichrospher - $100 \mathrm{RP} 18$ (250 x $4.6 \mathrm{~mm})$; eluent: methanol/ $0.5 \%$ orthophosphoric acid $(1: 1 \mathrm{v} / \mathrm{v})$; flow-rate: $1.2 \mathrm{~mL}$ min $^{-1}$; detection: $370 \mathrm{~nm}$. Peaks: 8, quercetin (8.2 min); 9, kaempferol $(13.0 \mathrm{~min})$.

In conclusion, the phenolic compounds detected in acerola may be classified in two categories; phenolic anthocyanin pigments and non-anthocyanin phenolics. The pigments detected were a 3,5-diglycosilated malvidin, a 3-monoglycosilated cyanidin and pelargonidin. Nonanthocyanin phenolic compounds identified were pcoumaric acid, ferulic acid, caffeic acid, chlorogenic acid, kaempferol and quercetin.

\section{Acknowledgements}

The authors would like to express their gratitude to Dr. M.C. Guedes for technical assistance on paper chromatography and useful discussions and CNPq, FAPERJ, CAPES and FUJB (Brazil) for financial support. Author LCT is recipient of a fellowship from $\mathrm{CNPq}$.

\section{References}

1. Jackman, R.L, Smith, J.L In Natural Food Colorants; Hendry, G.A.F.; Houghton, J.D., ed., Blackie Academic \& Professional: London, 1996, pp. 249-250.
2. Wang, J.; Sporns, P.; J. Agric. Food Chem. 2000, 48, 1657.

3. Simón, B.F.; Pérez-Ilzarbe, J.; Hernández ,T.; GómezCordovés, C.; Estrella, I.; J. Agric. Food Chem. 1992, 40, 1531 .

4. Gil, M.I.; Cherif, J.; Ayed, N.; Artés, F.; Tomás-barberán, F.A.; Z. Lebensm Unters Forsch. 1995, 201,361.

5. Gao, L.; Mazza, G.; J. Agric. Food Chem. 1994, 42, 118.

6. Strigl, A.W.; Leitner, E.; Pfaunhauser, W.; Z. Lebensm Unters Forsch. 1995, 201, 266.

7. Mazza, G.; Velioglu, Y.S.; Food Chem. 1992, 43, 113.

8. Mazza, G.; J. Food Sci. 1986, 51, 1260.

9. Bridle, P.; Timberlake, C.F.; Food Chem. 1996, 58, 103.

10. Francis, F.J. In Anthocyanins as Food Colors; Markakis, P., ed.., Academic Press: New York, 1982.

11. Guedes, M.C.; MSc. Dissertation (http://www.fea.unicamp.br), Campinas, Unicamp, Brazil, 1993

12. Giusti, M.M.; Wrolstad, R.E. In Current Protocols in Food Analytical Chemistry; Wrolstad R.E., ed., John Wiley \& Sons: New York, 2001. pp. F1.2.3-F1.2.4

13. Markakis, P.; Anthocyanins as Food Colors, Academic Press: New York, 1982.

14. Pazmiño-Durán, E.A.; Giusti, M.M.; Wrolstad, R.E.; Glória, M.B.A.; Food Chem. 2001, 73, 327.

15. Lees, D.H.; Francis, F.J.; Hortscience 1972, 7, 83.

16. Kader, F.; Rovel, B.; Girardin, M.; Metche, M.; Food Chem. 1996, 55, 35 .

17. Hasler, A.; Sticher, O.; J. Chromatogr. 1990, 508, 236.

18. Trugo, L.C.; Macrae, R.; Food Chem. 1984, 15, 219.

19. Harborne, J.B.; J. Chromatogr. 1958, 1, 473.

20. Dekazos, E.D.; J. Food Sci. 1970, 35, 237.

21. Timberlake, C.F.; NATCOL Quarterly Bulletin 1988, 1, 4.

22. Oomah, D.; Mazza, G.; J. Agric. Food Chem. 1996, 44, 1746.

23. Merken, H.M.; Beecher, G.R.; J. Agric. Food Chem. 2000, 48 , 577.

24. Espin, J.C.; Soler-Rivas, C.; Wichers, H.J.; Garcia-Viguera, C.; J. Agric. Food Chem. 2000, 48, 1588.

Received: July 10, 2003 Published on the web: August 9, 2004 